\title{
Postulaciones políticas en la novela colombiana ¡Viva Cristo Rey! de Silvia Galvis Ramírez
}

\author{
Politics applications in the novel ¡Viva Cristo Rey! by Silvia Galvis
}

\section{Resumen}

Este artículo se basa en la investigación titulada "Postulaciones políticas en la novela ¡Viva Cristo Rey! de Silvia Galvis” de la Universidad Cooperativa de Colombia, sede Bucaramanga, 2009, la cual se desarrolla a partir de la propuesta de la triple mímesis de

Paul Ricoeur.

Las motivaciones que se pueden encontrar para la producción de la obra en la vida de la escritora, tales como la lucha partidista ocurrida en Colombia durante la primera mitad del siglo XX, conforman la primera parte del trabajo.

El análisis literario de los personajes Alejo Coronado (líder del partido liberal) y José

Beatriz Guerrero (líder del partido conservador) conforma la segunda parte, y, finalmente, la puesta en escena de un guión de teatro construido por estudiantes de décimo

grado constituye la propuesta pedagógica que se implementará en una institución educativa de Bucaramanga.

Palabras clave Escuela, novela, pedagogía, violencia.

Abstract

This article is based on the investigation "Political proposals in the book ;Viva Cristo Rey! written by Silvia Galvis” of Universidad Cooperativa de Colombia, Bucaramanga, 2009, which is developed from the application of the triple mimesis of Paul Ricoeur The motivations that can be found for the production of the play in the life of the writer, such as the partisan struggle that occurred in Colombia during the first half of the twentieth century, form the first part of the job. Literary analysis of characters Alejandro Coronado (leader of the Liberal Party) and Jose

Beatriz Guerrero (leader of the Conservative Party) forms the second part, and finally staging a dash of theater built for tenth grade students. It is the proposal of teaching to be implemented in a school of Bucaramanga.

Keywords School, novel, education, violence.
Leydy-Yohana Villarreal-Espinosa* Ingrid-Johanna Delgado-Guevara ${ }^{\text {** }}$

Docente que avala el artículo:

Jairo Castro Neira ${ }^{* * \%}$

Recibido: 4 de marzo del 2011

Aprobado: 18 de abril del 2011
Cómo citar este artículo: Villareal-Espinosa, Leydy-Yohana y Delgado-Guevara, IngridJohanna (2011), "Postulaciones políticas en la novela colombiana ;Viva Cristo Rey! de Silvia Galvis Ramírez", en Rastros Rostros, vol. 13, núm. 25, pp. 87-92.

Estudiante de Licenciatura en Educación Básica con énfasis en Humanidades, Lengua Castellana e Inglés de la Universidad Cooperativa de Colombia, sede Bucaramanga. Correos electrónicos: leidyvillarreal@campusucc.edu.co, leydysita1012@hotmail.com

** Estudiante de Licenciatura en Educación Básica con énfasis en Humanidades, Lengua Castellana e Inglés de la Universidad Cooperativa de Colombia, sede Bucaramanga. Correos electrónicos: ingrid.delgado@campusucc.edu.co, johanitadelgue05@hotmail.com

*** Licenciado en Idiomas de la Universidad Industrial de Santander. Magíster en Semiótica (Tesista) de la Universidad Industrial de Santander. Docente de la Universidad Cooperativa de Colombia, sede Bucaramanga. Correo electrónico:jairo.castro@campusucc.edu.co 


\section{Introducción}

ste artículo proviene de una investigación que se desarrolló en la Licenciatura en Educación básica con énfasis en Humanidades, lengua castellana e inglés de la Universidad Cooperativa de Colombia, titulada "Postulaciones políticas en la novela colombiana del siglo XX”, que en su fase final abarcó un corpus de novelas correspondientes a la literatura de la violencia urbana durante la última mitad del siglo.

La investigación se realizó a partir de la obra literaria ¡Viva Cristo Rey! de Silvia Galvis, en la que se refleja la guerra de los partidos políticos liberal y conservador durante la época denominada la violencia colombiana. El trabajo toma como referentes a los dos personajes principales de la obra, quienes representan los dos partidos políticos tradicionales que se enfrentan por defender sus ideales.

Quisimos tomar esta problemática y llevarla al aula de clase para evidenciar los problemas políticos y sociales a partir de la novela del siglo XX. Esto implicó que se realizaron varias investigaciones para evidenciar la problemática del país en el siglo $\mathrm{XX}$, y saber qué estaba viviendo la autora de este libro, motivo por el cual la llevó a publicar.

Este proyecto busca que los estudiantes de lengua castellana del grado décimo aumenten el gusto por la lectura a partir de la novela ;Viva Cristo Rey!, del siglo $\mathrm{XX}$, en la que se abordan temas de interés como la política, sexo, religión, la mujer, y la violencia vivida desde el siglo XX y comparada con la situación actual para llegar a una reflexión de lo vivido.

Finalmente, esta investigación plantea una propuesta como estrategia para incentivar a estudiantes y profesores, haciendo que la lectura sea agradable y que se realice con los objetivos de investigar, obtener conocimiento y mejorar el hábito de lectura. Este artículo se estructura partir de las vivencias del autor, el análisis de la obra y la propuesta pedagógica, y la importancia de ésta.

\section{Metodología}

El presente artículo, "Postulaciones políticas en la novela colombiana del siglo XX", da a conocer al lector de forma detallada la novela ;Viva Cristo Rey! Para esto se enfocó en la vida del autor, los hechos históricos y la obra como guía a nuestra investigación. La investigación nos lleva a conocer mas a fondo de la historia de Colombia en lo que respecta a sus costumbres la época de la violencia y los ideales de las personas que conformaban los pueblos, para luego compararla con la época actual, teniendo en cuenta que la historia en la obra no es solo ficción, sino que se asemeja a la realidad del siglo XX, lo cual hace referencia a la época en que Silvia Galvis, autora del libro, vivió su infancia. Hace parte de su realidad el enfrentamiento los idearios políticos de aquella época, caracterizados por la desigualdad y mucha violencia.

Una de las necesidades del lector ha sido comprender e interpretar el quehacer literario: la práctica social perteneciente al mundo real pero también al imaginario, dado que la literatura responde, en varias de sus expresiones, a procesos que marcan el devenir de lo que se expresa. Así, es posible reconocer en la literatura una conciencia de la historia y el anhelo de transformación mediante una escritura que al renovar el sentido profundo del pasado adquiera valor como producción estética. Paul Ricoeur plantea como supuesto la "triple mímesis” (mímesis I, mímesis II y mímesis III), contrapuesta a la "semiótica del texto". Según Paul Ricoeur, se producen tres fases en la mímesis en las que interviene el análisis del texto, las cuales constituyen una mediación entre el tiempo y la narración de la obra. La mímesis I se relaciona con el autor, la mímesis II se relaciona con la obra, y la mímesis III con el lector.

La novela de Silvia Galvis está enmarcada en un conflicto social que se viene desarrollando en Colombia desde hace muchos años, dado que en el 
siglo XX se vive la guerra de los mil días, un hecho histórico y representativo de la época. También se evidencia la ambición de los partidos políticos que veían en la guerra un medio para conquistar el poder y retenerlo, matando personas inocentes o sacrificándolas al mandarlas a la guerra.

Desde 1940, en Colombia hay una hegemonía liberal en el gobierno. El país está gobernado por Eduardo Santos quien se opone a Mariano Ospina Pérez. Jorge Eliécer Gaitán entra a liderar la izquierda liberal; paulatinamente se consolida el partido conservador, dirigido por Laureano Gómez. El acontecimiento más notable en el siglo XX ocurre el 9 de abril de 1948 con la muerte del caudillo liberal Jorge Eliecer Gaitán, hecho que precipitó al país a una violencia inusitada que se ensañó especialmente contra el campesino y enfrentó a muerte a los dos partidos tradicionales.

En 1991, Silvia Galvis publica ;Viva Cristo Rey!, siendo esta novela el resultado de una investigación histórica y social en la que se desarrollan temas como el amor, el sexo, la ambición, la injustica social y el feminismo.

La autora nace en Bucaramanga (Colombia) el 24 de noviembre de 1945. Se inclina por la literatura, el periodismo y la historia, de forma que es considerada una de las pioneras del periodismo independiente en Colombia. Inició su vinculación a Vanguardia Liberal como periodista en 1980, creando el departamento investigativo, trabajo que asumió con total entereza, dado que le apasionaba luchar contra la corrupción reinante en el país. Recibe una mención especial por periodismo investigativo del Premio Nacional Simón Bolívar el 13 de noviembre de 1982. Desde 1979 mantenía su columna "Vía Libre", que fue la más leída del diario en su época y en la cual, con gran valentía y sin tapujos, sin censura, llamaba a las cosas por su nombre, y sin ninguna claudicación enfrentó siempre todos los problemas de corrupción, de protección de los derechos humanos y de defensa de la comunidad santandereana. En Vanguardia Liberal se hizo acreedora al premio Simón Bolívar a la mejor columnista del país en 1987. Como escritora e historiadora le deja a Colombia y América Latina una extensa obra en la que destaca su pluma y su capacidad como investigadora.

Algunas de sus obras son ;Viva Cristo Rey! (1991), Vida mía (1994), Sabor a mí (1995), Los García Márquez (1996), De la caída de un ángel puro por culpa de un beso apasionado (1997), De parte de los infieles (2001), Soledad, conspiraciones y suspiros (2002), La mujer que sabía demasiado (2006).

En 1991 aparece ¡Viva Cristo Rey!, obra que trata del enfrentamiento permanente entre liberales y conservadores en el siglo XX. Este relato se desenvuelve en dos pueblos de Santander llamados Onán e Himeneo, en el que narra la alianza de la iglesia católica junto con el partido conservador, de la cual se ven afectadas las mujeres. En esta obra se vive un ambiente de odio, de rencor, de humor y de enfrentamiento permanente.

La obra comienza presentando a un niño huérfano llamado Alejo Coronado, quien es el hijo de Jesús Coronado, un ídolo del partido Liberal que quiere que su hijo sea el representante del partido al cual le ha venido siendo fiel. Por medio de una carta escrita por su padre antes de morir, es que Alejo comienza la guerra contra los conservadores, notando que su padre nunca se rendiría ante ellos y quien pensaba que los Liberales habían ganado la guerra:

Nueve días antes de que el presidente de la república proclamara el fin de la guerra, a Jesús Coronado lo perforó una bala de pólvora negra que le reventó el estómago. Antes de morir, maldijo al papa, juró lealtad eterna al partido liberal y escribió una carta a su hijo exigiéndole la promesa de que jamás se rindiera a los conservadores. Se fue con la certidumbre feliz y evocadora de que los liberales habían ganado la guerra y que la República estrenaba siglo sin el clero gobernando la patria y mandando al gobierno (Galvis, 1991, pp. 11-12).

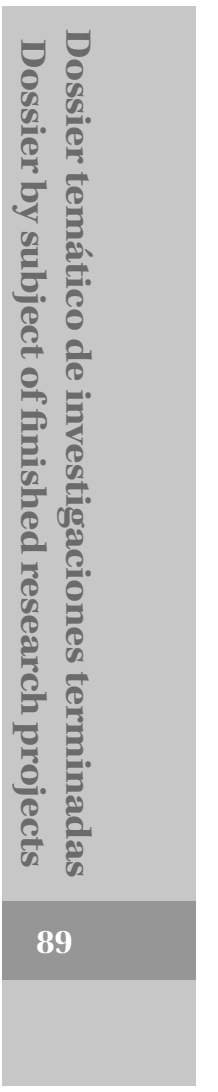

Revista Rastros Rostros - Volumen 13, Número 25 - enero-junio 2011 
En ;Viva Cristo Rey! se refleja la guerra de partidos por obtener el poder, protagonizando fuertes discusiones para mantener firmes sus promesas:

- La voz de Dios es la voz del pueblo- dijo José Beatriz. El problema con ustedes los liberales es que no se resignan a que los conservadores ganemos las elecciones porque somos católicos como ordena la constitución.

- Ni Dios ni la constitución, sino el fraude maloliente de los votos que es la voz del diablorespondió Alejo con el desdén dibujado en los labios.

- La constitución y el concordato que en este país tiene el valor de las sagradas Escrituras- insistió José Beatriz, inmutable.

- La infalibilidad de la maquina electoral y del clero todo poderoso- cortó Alejo.

- Aquí, el que escruta elige y esa es también una verdad infalible- recordó José Beatriz

- En este país las elecciones son batallas, lo dijo bolívar y lo digo yo te lo voy a demostrar muy pronto- concluyó coronado (autor 1991, pp. 90-91).

En la obra ;Viva Cristo Rey! se narran los acontecimientos del 9 de abril de 1948, llamado Bogotazo, del cual fueron partícipes sus personajes, dirigidos por Alejo Coronado, líder del partido liberal y José Beatriz Guerrero, líder del partido conservador.

Silvia Galvis no sólo narra la guerra de partidos políticos, sino que partir de sus personajes deja ver cada una de sus historias, en las que no sólo se refleja el poder político, sino temas como la mujer, y cómo ésta fue tomando fuerza para su liberación, para así ganar una guerra que daba por perdida. Esto lleva a revelar una guerra constante por el poder, la ambición, la liberación, y el valor a la vida, de esta manera, la obra narra el sufrimiento de una joven que, por ser campesina y no tener dinero, es abusada por el líder del partido conservador. A partir de este hecho podemos decir que la obra esta diseñada para enfocar diferentes vertientes, como lo son el valor y respeto a la vida.

Silvia Galvis muestra en Alejo Coronado un personaje con mucho sentimiento amoroso, lo que hace que se convierta en cómplice de las mujeres, ya que algunas de ellas juega con su sentimiento para sacar provecho de sus planes políticos. "Desde el día en que llegó Alejo a la capital, Alejo Coronado supo que su vida sería un eterno conflicto entre el deseo y la templanza que jamás sería aliada firme de su corazón” (Galvis, 1991, p. 63).

La novela pertenece al género narrativo; sus personajes, su tiempo y espacio hacen que la novela sea contada con hechos reales y ficticios, lo que permite hacer que la obra sea más fácil de leer y entender, permitiendo al lector imaginar el espacio y el tiempo en el que ésta se desenvuelve.

Para aquellas personas que han tenido la oportunidad de conocer dos pueblos divididos por el río Magdalena, entre Santander y Antioquia existen dos, llamados Barrancabermeja y Yondó, que se encuentran representados en la novela $;$ Viva Cristo Rey! como Onán e Himeneo. Se percibe entonces que Silvia Galvis se ubica en estos dos pueblos para contar su historia y poner de manifiesto la riqueza que tienen los municipios, como es el petróleo, y desde allí se desenvuelve parte de su obra literaria.

Respecto a los personajes, se encuentra que son partidarios políticos religiosos. Se evidencia su manera de vestir, su dialecto santandereano, y sus costumbres, como reunirse para ir a misa los domingos y salir a la plaza del pueblo a protestar a favor o en contra de los partidos políticos.

$\mathrm{Al}$ hacer la lectura de la novela podemos ver que se realiza en dos pueblos santandereanos llamado Himeneo y Onán, que no existen, pero que se llaman así porque la autora del libro es santandereana y quiso poner en evidencia lo que sucedía en el siglo XX en Santander, dado que este departamento también se vio afectado en la guerra de los mil días. Pasando a su composición, encontramos que la obra está escrita por capítulos y narra algunos de los hechos que fueron representativos para los partidos políticos, como lo fue el 9 de noviembre de 1948, con la muerte del caudillo liberal Jorge Eliecer Gaitán y el Bogotazo. La obra está narrada por un 
narrador omnisciente, quien sabe todo lo sucedido en la vida de cada personaje, pero nunca se sabe en realidad quien es. Esta obra se hace interesante al ser contada con detalles sobresalientes de la vida privada de cada personaje. La obra se abordadesde lo histórico y desde un análisis profundo.

Para poner en práctica el proyecto de investigación, se quiso hacer una propuesta pedagógica para llevar al aula con el objetivo de cambiar o crear una estrategia con el fin de que el estudiante lea e investigue la obra que se le da, ya que la obra se presta para que se haga una investigación profunda sobre costumbres, vestuario y cómo era la guerra bipartidista. Para esto se plantea una obra de teatro como método didáctico para que la lectura no se pierda, sino que sea clara y que cree conocimiento en el estudiante para que mejore su intelecto y su hábito de lectura. Se plantea como objetivo leer la obra para luego hacer un guión y evidenciar la problemática del país a partir de la novela, además de crear y promover en los alumnos la importancia de expresar los sentimientos, conflictos o alegrías a través de la representación teatral.

\section{Resultados}

Después de realizar el análisis literario de la obra, se platea la manera de llevar la obra al aula de clase. Para esto se realizó una propuesta pedagógica para los estudiantes de décimo grado con el objetivo de motivarlos a la lectura a partir de la obra literaria ; Viva Cristo Rey!, por medio de una obra de teatro, lo cual permitirá que los estudiantes den posibles soluciones del conflicto que se vive en el país desde el siglo XX.

Se plantea la lectura de ¡Viva Cristo Rey! ya que habla de temas de interés para los estudiantes, como son la guerra de partidos políticos, la violencia, el amor, el sexo, la ambición, la injusticia social y el feminismo; pero el énfasis, el tema de enfoque es la guerra de partidos políticos del siglo XX. Con esta lectura se resalta la importancia de la literatura en el aula, dado que le brinda al estudiante una oportunidad para obtener información y crecer el hábito de lectura, siendo éste un medio de desarrollo intelectual para el estudiante y para que la lectura cree el gusto de leer. Debemos tomar conciencia de que la lectura en los colegios se ha perdido porque en ocasiones el docente no incentiva al estudiante y eso hace que el estudiante esté obligado a leer un libro que no es de su interés y de temas que no corresponden a su edad. Para esto se propone la lectura de libros como ¡Viva Cristo Rey!, que consta de diversos temas y cuenta historias muy interesantes. Por eso, en la propuesta se habla de obra de teatro, una actividad que para los estudiantes se torna controvertida, ya que van a tener que representar un personaje que les parezca acorde a sus capacidades. Además, el docente va tener la oportunidad de hacer una clase didáctica y creativa, lo cual indica que los estudiantes van aprender de una manera llamativa y se va hacer más significativo el aprendizaje. Para lograr una buena propuesta se debe trabajar acorde con los gustos del estudiante, haciendo que opinen sobre cómo les gustaría que se desarrollara el proyecto, de forma que sean ellos los que tomen la iniciativa para una buena clase, siendo la opinión del estudiante importante para el desarrollo de la propuesta.

Es de suma importancia poner algunas reglas para que el estudiante se cuestione el porqué de la lectura, y aproveche la oportunidad que le da el autor de que investigue acerca de la novela para que se dé una participación colectiva, se aprenda de sus compañeros e incentive el hábito de la lectura sin que se sienta como una obligación, sino que parta de su gusto, de forma que lo haga por sí solo. Con la lectura de la novela se lleva a conocer más sobre la historia de Colombia, indagando sobre el pasado y en concreto sobre la violencia del siglo XX.

\section{Conclusiones}

Al momento de realizar la investigación surgen varias inquietudes y por esto se lleva a cabo el proyecto. Se realizó un trabajo extenso con un tiempo dedicado 
a obtener diferentes respuestas. Esta investigación se da inicio por medio de una selección de libros, los cuales se fueron sorteando para que cada grupo obtuviera su novela, seguidamente se inicia una lectura de cada novela, la cual debía ser socializada. Para la investigación de la novela nos debimos desplazar a las bibliotecas en búsqueda de información acerca del siglo en el que se desenvuelve la obra y obteniendo información de diferentes historiadores y autores como William Ospina.

Durante el proceso de la investigación notamos la importancia de leer y estar informado sobre hechos importantes y controversiales en el país, por esta razón nos vimos obligados a presentar una solución para que la lectura se haga más constante en el diario vivir de la persona, pues ayuda a construir argumentos, y a cuestionarse más sobre la vida.

Esta obra enriquece nuestro conocimiento acerca de la creación de los grupos políticos que conforman nuestro país. Además, nos pone al tanto de los acontecimientos que marcaron el siglo XX, que son representativos incluso hoy y mañana, y por esto se hace importante la lectura y la necesidad de alentar a los estudiantes a que hagan una lectura interesante con unos buenos argumentos, además de la solución que se ofrece a partir del teatro, como fuente fundamental en la elaboración de la obra. Es de gran importancia para nosotras como futuras docentes pensar en una estrategia y una solución para que la lectura y la escritura se hagan más significativas y llamativas en el colegio, donde está la oportunidad de formar estudiantes con criterios políticos, estudiantes que sean amantes de la buena lectura y con la capacidad de debatir cualquier tema presentado.

\section{Referencias}

Galvis, S. (1991), ¡Viva Cristo Rey!, Planeta, Bogotá.

Ospina, W. (1997), ¿Dónde está la franja amarilla?, Bogotá, Verticales de Bolsillo.

Puente Brugés, J. (2009, 21 de septiembre), "Falleció Silvia Galvis Ramírez", Vanguardia Liberal, [en línea] disponible en http://www.vanguardia.com/ historico/40282-fallecio-silvia-galvis-ramirez, recuperado: 4 de abril del 2011. 